\title{
Representações sociais de escrita em curso de formação docente: objeto de ensino e objeto de inserção nas práticas letradas acadêmicas
}

\author{
Hermano Aroldo Gois Oliveira* \\ Denise Lino de Araújo**
}

\begin{abstract}
Resumo
Este trabalho justifica-se por direcionar a sua atenção para o aprendiz que se utiliza da escrita para se inserir nas diversas práticas comunicativas comuns à universidade. Neste sentido, motivado pelo problema de pesquisa - Que representação social sobre a escrita em Letras é revelada por graduandos? -, tem-se por objetivo descrever a representação de escrita acadêmica em cursos de licenciaturas em Letras à luz do fenômeno das representações sociais, teoria desenvolvida por Moscovici (2013) e colaboradores (JOVCHELOVITCH; GUARESCHI, 1994). A metodologia utilizada é de base qualitativa, a qual segue os procedimentos da pesquisa experiencial (MICCOLI, 2014) e da pesquisa exploratória (GIL, 1994). Em se tratando da coleta de dados, foi aplicado 1 (um) questionário e realizadas 3 (três) sessões reflexivas com grupos de graduandos de Cursos de Letras de 3 (três) instituições de nível superior, localizadas no estado da Paraíba, Brasil. O corpus é constituído por um conjunto de depoimentos. Os resultados mostram que os saberes revelados por graduandos servem de fomento para a formulação da representação social de escrita acadêmica como objeto de ensino, apresentado pelos cursos em questão; e objeto de inserção nas práticas letradas, requisitado no ensino superior.

Palavras-chave: Escrita acadêmica. Representações sociais. Letras. Ensino superior. Linguística Aplicada.
\end{abstract}

Recebido em:30/04/2017

Aceito em:12/09/2017

\footnotetext{
* Doutorando em Linguística pelo Programa de Pós-Graduação em Linguística pela UFPB; mestre em Linguagem e Ensino pela UFCG.

** Professora associada da Unidade Acadêmica de Letras da UFCG, docente na graduação em Letras e nos Programas de Pós-graduação em Linguagem e Ensino e em Design da mesma IFES. Membro do grupo de pesquisa Teorias da Linguagem e Ensino e do GT da ANPOLL Ensino e a Aprendizagem na Perspectiva da Linguística Aplicada.
} 


\section{Introdução}

A partir da última década, o ensino da escrita em contexto universitário tem se voltado para a aprendizagem de gêneros e de suas relações sociocomunicativas. Essa abordagem de escrita reflete-se no modo de ensiná-la, pois, nela, este objeto passa a ser visto como uma prática social a qual está vinculada a situações concretas de comunicação. Assim, a sua aprendizagem pressupõe o contato com formas genéricas de escrita, organização, conteúdo e léxico apropriados às práticas desenvolvidas em determinados campo de atuação (BAZERMAN, 2015a; BAZERMAN, 2015b).

Nesse contexto, especificamente nos cursos de Licenciatura em Letras, onde se espera um significativo trabalho com a produção escrita, entre outros aspectos, deve se dedicar às dificuldades de escritura, a julgar pelo objeto de estudo/de ensino - a língua(gem), e também, supostamente, deve preparar o acadêmico para trabalhar com o ensino de escrita, na educação básica, bem como propor a relação entre a reflexão teórica e a aplicação prática. Todavia, recentes pesquisas da área mostram que nem sempre essa realidade é contemplada (HOFFNAGEL, 2010; MENEGASSI, OHUSCHI, 2007).

Por conseguinte, encontramos variado material didático ${ }^{1}$ com vista a orientar como ensinar - mas também como aprender - conceitual e estruturalmente a redação de gêneros textuais próprias do ensino superior. Esse acervo revela a preocupação de estudiosos com essa matéria que não é nova, prova disso são os inúmeros livros atuais e reeditados com o objetivo de contribuir para o acesso ao letramento acadêmico a partir (e não somente) da produção textual científica.

Nesse sentido, os estudantes de Letras, quando não têm uma formação qualificada, tendem a reproduzir suas experiências adquiridas durante a formação inicial (ROTTAVA, 2004). Isso se justifica porque o discente formula representação de escrita, sob a mesma perspectiva a qual lhe fora ensinada (MENEGASSI, 2003) e a ressignifica da maneira como a aprendeu. Ora, se sabemos que há consideráveis problemas no ensino da escrita na escola, a julgar pelos resultados de pesquisas voltadas aos exames nacionais (LINO DE ARAÚJO; SILVA, 2010), precisamos

1 Dentre o acervo, destacamos Comunicação em prosa moderna (2010), de Othon Moacyr Garcia; a coleção Leitura e Produção de Textos Técnicos e Acadêmicos (2007), coordenada por Anna Rachel Machado; a obra Produção Textual na Universidade (2010), de Désirée Motta-Roth e Graciela Rabuske Hendges; os livros Como se faz uma tese e Professora, como é que se faz?, de Eco (2010) e de Silva (2012), respectivamente, dentre outros. 
redirecionar o nosso olhar aos cursos de formação incumbidos da função de ensinar essa prática de letramento.

Entendemos que, uma vez inserido no ambiente acadêmico, o estudante (re)constrói a sua forma de compreender a escrita, isso porque acreditamos que a subjetividade do sujeito, aquilo que traz consigo desde o início da sua formação escolar, juntamente com o ambiente social, caracterizado pelo curso de formação inicial, onde está inserido, atuam como elementos preponderantes para a forma de compreender o mundo, para as representações (re)construídas.

Sendo assim, a partir desta realidade e orientados pela questão de pesquisa Que representação social sobre a escrita em Letras é revelada por graduandos?, o presente artigo tem como objetivo geral (1) descrever a representação social de escrita formulada em cursos de formação docente, a partir de depoimentos de licenciandos ingressos e egressos em Letras. E, como objetivos específicos, (1.1) analisar os saberes formalizados sobre a escrita mobilizados no âmbito universitário, mas também (1.2) discutir como estes saberes interferem no modo como os sujeitos investigados a representam, uma vez que "uma representação social existe no e pelo discurso" (PY, 2003, p. 17).

Dessa forma, além desta introdução, na qual, brevemente, situamos o contexto do tema investigado no cenário brasileiro, este artigo apresenta mais quatro tópicos, os quais são: (1) síntese da fundamentação teórica, na qual discutimos acerca do fenômeno das Representações Sociais cunhada por Moscovici (2013). (2) Procedimentos metodológicos, na qual caracterizamos a natureza e o tipo da pesquisa que originou este artigo, bem como apresentamos os sujeitos participantes e o contexto de geração de dados. (3) A discussão de dados, subdividida em mais dois tópicos, quais são: escrita acadêmica orientada e escrita acadêmica normatizada. O primeiro visa desvelar e discutir a respeito do modo como a escrita é apresentada nos cursos. O segundo, em como este objeto em questão é naturalizado na academia. Por fim, apresentamos as conclusões a que chegamos.

\section{Síntese dos fundamentos teóricos}

A Teoria das Representações Sociais vincula-se ao trabalho de Moscovici (2013). Nela, o autor estabelece avanços ao romper com a tradição individualista ou "psicologista" que se instalara na psicologia social e as consequentes dificuldades 
desta teoria, como, por exemplo, a ambição de ir além dos estudos para o quais se propôs a redefinir os problemas e conceitos da psicologia social, além de pontuar os terrenos que demarcam a representação social, como a tradição sociológica.

Com a visão de representação, o teórico rompe com a concepção individualista - também chamada de individualização da psicologia social, por Le Boh (1985 apud FARR, 1994) -, que ganhara força na psicologia social, a partir da separação dos fenômenos "individual" e "coletivo", empreendida por Durkheim. Em seus estudos, o psicólogo social, em uma tarefa arriscada, mas também original, direciona o seu olhar para a relação sujeito e objeto, os quais são vistos simetricamente. Para ele, "o indivíduo tanto é um agente de mudança na sociedade como é um produto dessa sociedade" (FARR, 1994, p. 51). Isso porque o sujeito e o objeto coexistem inter-relacionados a um mesmo campo de atividade, como afirma,

[...] não existe um corte dado entre universo exterior e o universo do indivíduo (ou do grupo), [...] o sujeito e o objeto não são absolutamente heterogêneos em seu campo comum. O objeto está inscrito num contexto ativo, dinâmico, pois que é parcialmente concebido pela pessoa ou a coletividade como prolongamento de seu comportamento [...] (MOSCOVICI, 2013, p. 61).

Nesse sentido, ao notarmos que a teoria das Representações Sociais considera que tanto o sujeito quanto o objeto partilham mutuamente de uma mesma construção, e que, por sua vez, a realidade é construída com base nessa interação, reconhecemos, pois, a existência de um diálogo entre esta e os preceitos postulados pela corrente teórica do Interacionismo Sociodiscursivo (doravante, ISD), segundo a qual o indivíduo é compreendido como sujeito psicossocial (BRONCKART, 2012), isto é, as condições e as intervenções sociais assumem papel decisivo na formação das capacidades cognitivas do sujeito. Além desse aspecto, Assis (2016), a partir de releitura de Py (2003), considera três traços característicos para esta teoria, quais sejam: i) relevante na aplicação de interpretação de fenômenos complexos; ii) existente no/pelo discurso; e iii) difundida e circulada em um grupo social. Em relação aos três traços, interessa-nos sublinhar o segundo e o terceiro deles, haja vista que refletem a análise realizada neste artigo. Isso porque é por meio dos discursos que os sujeitos significam a compreensão que têm sobre a escrita mobilizada na universidade.

Trazido à cena o contexto da teoria, acrescentamos a noção de que, ao formulála, Moscovici (2013) declara que as Representações Sociais são geradas a partir 
da aplicação de dois elementos: objetivação e ancoragem. O primeiro remete à concretização de um símbolo, à materialização, ou seja, para o psicólogo, o indivíduo, a fim de conceber o objeto, precisa, necessariamente, materializá-lo, torná-lo real ao seu modo. Para ilustrar, o teórico chama a atenção, na psicologia, para descrição de patologias que, por vezes, se demonstram distantes da realidade dos sujeitos.

Se considerarmos, como ilustração desse conceito, o trabalho com os gêneros textuais na Linguística Textual, entendemos que a materialização destes se dá a partir do uso social, tal como proposto por Marcuschi (2010), para quem a sociedade emergente cria e recria gêneros em virtude de sua necessidade de interação. Desse modo, quando associamos esse processo para a representação de escrita, validamos a compreensão de um objeto que se modifica mediante o lugar de interação - as exigências de escrita na educação básica e superior, por exemplo.

O segundo elemento, ancoragem, para o psicólogo social, remete à explicação do objeto, ao modo como este pode ser interpretado, ou seja, uma vez concretizado (objetivação), o objeto precisa ser explicado, interpretado para que se torne real à sociedade. Entretanto, para que isso seja possível, é necessário que o objeto concretizado seja categorizado, rotulado, a fim de que se torne conhecido socialmente, e uma forma de sê-lo é por meio da classificação e nomeação.

Classificar, assim, para esta teoria, significa clarificar alguma coisa, tornar algo distinto; pois, aquilo que não recebe nome, que não é passível de classificação, não existe. Desse modo, essa tendência em classificar um objeto, seja por uma atitude de generalizá-lo ou, até mesmo, particularizá-lo, "não é, de nenhum modo uma escolha puramente intelectual, mas reflete uma atitude específica para com o objeto, um desejo de defini-lo como normal ou aberrante" (MOSCOVICI, 2013, p. 65) - e não só, mas também porque reflete a necessidade de apropriação desse objeto. Dito de outra forma, com atitude de clarificar as representações, necessariamente, o sujeito sociodiscursivo classifica o fenômeno a partir de inferências de outra realidade, que permite que o "novo" representado crie sua identidade. Em harmonia com essa atitude, Moscovici (2013) compreende a existência da atividade da nomeação, conforme será exemplificado na seção de discussão de dados, a seguir.

Essas duas atividades parecem caminhar juntas, porque é inviável classificar sem, ao menos, dar nome. "Ao nomear algo, nós o libertamos de um anonimato perturbador para dotá-lo de uma genealogia e para inclú́-lo em um complexo de 
palavras específicas, para localizá-lo, de fato, na matriz de identidade de nossa cultura" (MOSCOVICI, 2013, p. 66. Grifo do autor). Logo, na nossa sociedade, a atividade de nomear, de "batizar" algo ou alguém, tem valor especial, pois evidencia uma atitude necessária para que tome forma, ligação com outra imagem. Contudo, é importante considerar, ainda, que esse valor especial não se dá apenas em relação ao objeto em si, mas também para a relação que se estabelece entre o objeto e os sujeitos que o nomeiam.

Não por acaso, Moscovici (2013), em suas ponderações, provou três consequências resultantes da atividade de dar nomes, as quais são: i) descrição e aquisição de características; ii) distinção a partir dessas características; e iii) aceitação coletiva. Para melhor compreensão dessa realidade, tomamos, do mesmo modo, por exemplo, as definições de gênero e tipo textual empreendidas na Linguística Textual. Ora, de acordo com autores renomados na área (ADAM, 1992; TRAVAGLIA, 2002; MARCUSCHI, 2008), não há como tomar um conceito pelo outro.

Para que esses conceitos tomassem formas, fossem concretizados e reconhecidos enquanto tais, foi necessário propor definições, mas também nomeações, que permitissem aos pesquisadores compreender as diferenças com maior facilidade.

Desse modo, Marcuschi (2010), em suas discussões sobre aspecto teórico e terminológico, diz que a expressão "tipo textual" designa, propriamente, uma espécie de sequência teoricamente definida pela natureza linguística típica de sua composição (que envolve aspectos lexicais, sintáticos, tempos verbais, relações lógicas, entre outros). Além disso, o autor esclarece que há um número limitado dos tipos textuais classificados como narrativo, descritivo, argumentativo, dialogal, expositivo e injuntivo. Já a respeito dos gêneros textuais, o pesquisador afirma ser "uma noção propositalmente vaga para referir os textos materializados que encontramos na nossa vida diária e que apresentam características sociocomunicativas definidas por conteúdos, propriedades funcionais, estilo e composição características" (MARCUSCHI, 2010, p. 23). Diferentemente dos tipos textuais, os quais abrangem cerca de meia dúzia, os gêneros textuais não se pode precisar quanto são, dada a sua concretização, isto é, as circunstâncias sociais de utilização da linguagem, pois, sua nomeação é determinada pelo estilo, conteúdo, composição e função (MARCUSCHI, 2010).

É perceptível o interesse comum da nossa sociedade em nomear algum fenômeno emergente a fim de torná-lo real. Essa prática não se diferencia das 
representações sobre escrita, em que, por sua vez, sujeitos inseridos socialmente em uma mesma comunidade procuram tanto classificar quanto nomear a escrita de acordo com as especificidades comuns da sua área. Assim, pois, esses mecanismos são necessários à transformação que fazemos do não familiar ao familiar, por transferi-lo à nossa própria esfera particular, nosso lugar de conforto, que nos permite comparar e interpretar para, por fim, como considera o teórico social, reproduzir entre aquilo que podemos ver e tocar e, consequentemente, controlar. Tais mecanismos só são possíveis quando os chamados universos reificados e consensuais atuam simultaneamente para moldar a nossa realidade (MOSCOVICI, 2013).

A respeito desses universos, Sá (1995) esclarece que, em uma sociedade moderna, o novo, aquilo que se torna familiar, real, é, com frequência, gerado ou formulado por meio dos universos reificados da ciência, da tecnologia ou das profissões especializadas. Em outras palavras, estes universos remetem às novas descobertas ou teorias, invenções e desenvolvimentos técnicos, produções políticas, isto é, típicas do conhecimento científico, advindo da academia (MOSCOVICI, 2013). Por sua vez, os universos consensuais admitem a existência de uma realidade social. É nele que operam os processos pelos quais o não familiar passa a ser familiar, quando se torna, de fato, socialmente conhecido, aceito e concretizado.

Desse modo, fundamentados nos aportes desta teoria, interessa-nos interpretar as ideias que um grupo de sujeitos (caracterizados a seguir), inseridos em um âmbito de formação de nível superior, compartem sobre um mesmo objeto. Isso porque se trata da "ideia de um conhecimento construído por um sujeito ativo em íntima interação com um objeto culturalmente construído, que revela as marcas tanto do sujeito como do objeto, ambos inscritos social e historicamente" (TRINDADE, SANTOS; ALMEIDA, 2011, p. 102).

Além do já posto, ao considerarmos que as representações sociais são mediadas pela linguagem, como também que são formuladas a partir do caráter dinâmico em que se opera uma sociedade vigente, reconhecemos que o estatuto das representações não pode ser explicado apenas por teoria com foco no plano das ideias, das construções simbólicas. Para tal, recorremos à proposta do ISD, cuja tese central atesta que a linguagem se faz presente no interior do desenvolvimento humano. 
Assumimos esse interesse, primeiro, dado o estatuto com o qual se valida a teoria, a saber, como "ciência do humano" (BRONCKART, 2006, p. 10); isso oportuniza uma análise significativa das condições humanas que permitem a constituição das representações; segundo, porque o ISD defende que as "[...] propriedades específicas das condutas humanas são o resultado de um processo histórico de socialização, possibilitado especialmente pela emergência e pelo desenvolvimento dos instrumentos semióticos" (BRONCKART, 2012, p. 21).

Desse modo, tal como sustenta a corrente teórica, a linguagem não é vista apenas como um meio de expressão de processos de ordem psicológica, mas sim, como instrumento fundador e organizador desses processos em suas dimensões humanas. O que significa que não apenas a linguagem, mas as condutas ativas (ou como convém chamar, o agir) e o pensamento consciente são tomados como unidades de análise.

Nessa corrente, a linguagem só existe nas línguas naturais, as quais, por sua vez, só existem nas chamadas práticas verbais, nesse agir dirigido, configurado pelo discurso. E ao ser vista como processo ativo e criativo, a linguagem se reproduz a si mesma. Sob essa ótica, a linguagem desenvolve-se em duas teses, as quais fundamentam o ISD: a primeira assegura que a atividade de linguagem tanto produz objeto de sentido quanto é constitutiva das unidades representativas do pensamento humano; a segunda indica que a atividade de linguagem é vista como atividade social, e que, o pensamento traduzido pela atividade de linguagem é tanto semiótico quanto social (BRONCKART, 2008, 2012).

\section{Procedimentos Metodológicos}

A pesquisa ora apresentada é de natureza qualitativa. E assim se constitui porque, de acordo com Bortoni-Ricardo (2008), não busca relações entre fenômenos nem cria leis universais, mas sim procura entender, bem como interpretar fenômenos e processos socialmente situados em um dado contexto.

No que concerne à geração dos dados, a pesquisa se apresenta em sua classificação híbrida, do tipo exploratória-experiencial. Recorremos à metodologia exploratória porque, de acordo com as considerações de Gil (1994), esse tipo de pesquisa tem por finalidade primordial desenvolver, esclarecer ou até mesmo modificar conceitos já formulados outrora, com vistas à caracterização de 
problemas mais precisos. Recorremos também à outra modalidade de pesquisa, a experiencial, porque, ao privilegiar a voz dos sujeitos colaboradores, vistos como testemunhas legítimas de eventos e processos de ensino/aprendizagem (Cf. MICCOLI, 2014), priorizamos a interação com aquele que vivencia o contato com a escrita a partir da sua experiência adquirida no ambiente de formação acadêmica.

Ademais do método oportunizado por essas abordagens, beneficiamo-nos também de duas técnicas de pesquisa, quais sejam: questionário e sessão reflexiva. O questionário foi utilizado para nos ajudar a identificar práticas de letramentos, perfil socioeconômico, como também para nos informar sobre a formulação das perguntas a serem questionadas na sessão reflexiva. Esta - por sua vez, com gravação em áudio/vídeo - apresentada por Liberali et. al (2003), foi utilizada a fim de dar voz aos graduandos em seus ambientes de formação, bem como oportunizar momentos de colaboração e negociação entre eles.

Para essas autoras, as sessões são espaços colaborativos que permitem aos que assim participam conversar e negociar suas "agendas" para análise e interpretação de suas ações/escolhas em locus específico. Essa técnica está relacionada à atividade de caráter crítico-reflexivo do participante. Além disso, o trabalho com as sessões de discussão, como assim também são chamadas, inserem os participantes em um discurso de base argumentativa, orientando para propor questionamentos de caráter social, político e cultural (LIBERALI, et. al 2003).

No total, foram três sessões reflexivas ${ }^{2}$ realizadas com 33 (trinta e três) estudantes universitários de cursos de Letras vinculados a três instituições de ensino superior (duas públicas e uma privada), localizadas no estado da Paraíba, Brasil. Esses colaboradores - do sexo masculino e feminino com faixa etária entre 18 a 50 anos -, apresentam perfis distintos, dentre os quais bolsistas ou voluntários de projetos científicos (de iniciação científica, de iniciação à docência, de educação tutorial e de monitoria), educadores em exercício informal (aulas de reforço ou substitutos na educação básica, em regime celetista) ou formal (educação básica).

O corpus analisado é constituído por um conjunto de depoimentos de graduandos ingressos e egressos, transcrito a partir de normas de transcrição adaptadas de Marcuschi (2001) e categorizado conforme unidades singulares identificadas no procedimento referente à leitura dos dados. Desse modo, organizamos a análise

$2 \mathrm{Na}$ sessão reflexiva 1 , realizada em um auditório da instituição pública 1 , contamos com a participação de 15 (quinze) graduandos; na sessão 2, realizada em uma sala de aula da instituição privada, contamos com 11 (onze) graduandos; na sessão 3, realizada em uma sala de aula da instituição pública 2, contamos com 7 (sete) participantes. 
por meio de duas categorias, quais sejam: a) escrita acadêmica orientada; e b) escrita acadêmica normatizada.

\section{Discussão dos Dados}

Para os graduandos dos cursos de Letras das instituições indicadas, as representações sobre escrita comungam com o fato de que esse objeto deve "tornarse familiar, transferido para a própria esfera particular. Para isso, é necessário um esforço constante de tornar comum e real algo que é incomum (não familiar)" (MOSCOVICI, 2013, p. 58). Esse estado de concretude, de familiaridade com o objeto só é possível a partir do momento em que se passa a "coisificar" ou a classificar e dar nome a algo, neste caso, como veremos, à medida que esses sujeitos são questionados sobre as percepções que construíram sobre a escrita, com o propósito de tornar este objeto real e próximo da realidade na qual vivem, rotulações vão sendo realizadas, a partir de nomes ancorados no vocabulário da linguagem comum à academia.

$\mathrm{O}$ resultado ao qual chegamos aponta para o fato de que a representação de escrita, no curso de formação docente, apresenta características particulares que interferem no modo de agir desses sujeitos e que, uma vez apropriadas, permitemlhes se inserir nas diversas práticas letradas recorrentes no curso.

Nos itens a seguir, explicitamos os saberes evidenciados em depoimentos dos informantes a respeito da escrita usada na universidade. Para tal, reconhecemos duas evidências, a saber: orientação e norma. A primeira voltada para as condições de produção que se tornam mais reais no contexto universitário. A segunda voltada para a formalização do conteúdo, isto é, em como a escrita deve estar estruturada conforme exigências acadêmicas.

\subsection{Escrita Acadêmica Orientada}

É possível, dentro da representação de escrita inserida nas práticas requisitadas no curso, a compreensão de que esse objeto precisa ser apresentado, isto é, haver fornecimento de condições sociossubjetivas que orientam o trabalho com a escrita no âmbito acadêmico, pois, nesse contexto, a produção e socialização 
de conhecimentos tornam-se mais recorrentes. Para melhor compreender essa característica, seguem os dados:

$(1)^{3}$ quando eu penso na escrita de forma orientada você tem que ter um norte para escrever porque... se... você tem um artigo tem que saber que aquela escrita tem que ser orientada quanto à estrutura... introdução... fundamentação (SR3). (2) é o ensinar a refletir... quando a gente tem uma boa orientação... quando o professor realmente orienta a gente... nos faz refletir... então não é chegar assim e: "deixa eu corrigir!" não "o que é isso aqui? qual a razão desse primeiro parágrafo em relação com esse segundo?" "eita professora... nada!" é isso... é isso que é a escrita orientada e tem gente que vai passar os nove períodos e não vai ter isso (SR1).

Nos excertos acima, percebemos que o modo como a escrita é representada se harmoniza com a imagem de professor apontada pelos graduandos, visto como facilitador para o melhor desempenho da elaboração textual. Assim, a escrita, agora praticada, requer um trabalho reflexivo que exige dos graduandos maior empenho e dedicação com o que produzem e, do professor, o uso de procedimentos de encaminhamentos sistemáticos que favoreçam possibilidades de acesso ao conhecimento produzido na academia.

Parece-nos, ainda, que de acordo com os excertos, o desenvolvimento de uma melhoria a respeito do uso da escrita depende da forma como o professor formador encaminha as orientações de produção. Sem a sua participação, os graduandos demonstram ficar à margem da dinâmica existente no ensino superior, padecendo, assim, de uma orientação que permita resposta à demanda experienciada na academia, pois a falta dessa orientação reflete, possivelmente, uma formação científica fragilizada, como representado no depoimento: "e tem gente que vai passar os nove períodos e não vai ter isso" (SR1).

Certamente essa compreensão deve estar relacionada à necessidade de que os graduandos têm de se socializar em uma esfera diferente daquela a qual vivenciaram antes de ingressarem no ensino superior. O professor, nesse caso, assume papel essencial para essa socialização, já que permite um processo

3 Fonte: o código SR* representa a indicação de depoimentos coletados no conjunto da sessão reflexiva *1, *2 ou *3 realizada nas instituições já mencionadas à seção de metodologia, isto é, a primeira instituição pública representa o número $1 *$, instituição privada, o número $2 *$ e a segunda instituição pública, o número $3 *$. 
reflexivo do entendimento dos diferentes modos de uso da escrita advindos da academia, como podemos melhor compreender a partir do excerto que retrata a fala de uma participante em uma das sessões, sobre um evento sistemático que envolve a correção de textos escritos na academia:

(3) a professora juntamente comigo dizia: "eu fico com esta parte e você com essa" aí eu corrigia e a professora corrigia também então... a gente via e comparava aí ela fazia: "e por que você deu tanto nesse critério aí?" então isso daí... pra mim... eu aprendi muito com essa orientação específica em relação a didatizar a esse processo de escrita MAS por causa dessa experiência específica TALVEZ se fosse com outro professor que não tivesse essa preocupação talvez eu não teria como saber dessas coisas (SR1).

Nesse excerto, é possível afirmar que o professor cria oportunidades de vivência acadêmica para que, assim, o estudante, de fato, se insira na profissão, o que reforça a importância da imagem do professor para construção de representações sobre a escrita. Todavia, a partir do excerto acima, convém considerar a respeito da orientação metodológica do professor do componente curricular, uma vez que o depoimento expresso pelo informante favorece um modo do processo de ensino de escrita, o que não implica dizer que é padrão, comum a todos os docentes. Uma explicação para essa abordagem particular seria a consideração do currículo oculto, o qual os graduandos apresentam, e que reflete diretamente na orientação teórico-metodológica comum à prática do professor de determinada disciplina ofertada pelos cursos. Esse exemplo de trabalho didático com a escrita se apresentou em um contexto específico de orientação pedagógica. Entretanto, de modo geral, na apreciação dos depoimentos dos informantes, foi-nos possível desvelar que a escrita exigida nos cursos de Letras necessita de uma orientação, de um plano de ação que permita a quem é cobrado melhor direcionamento para atuação efetiva como escrevente e ator social na comunidade em que está inserido. Essa assertiva pode ser mais bem compreendida a partir dos excertos a seguir:

(4) o professor pode ajudar a você a traçar o seu objetivo também... então você sabe o que você quer pesquisar... pensa nisso... mas o professor pode ajudar a você delimitar objetivos específicos (SR2). 
(5) porque assim... (pensando) no ensino médio a gente não tinha esse professor pedindo pra gente... "releia... reescreva... melhore seu texto" não tinha e::: aqui a gente precisa disso... os professores pedem que a gente tente dominar mais o que a gente tá falando... às vezes fica alguma frase solta... ele manda contextualizar... então a gente tem toda uma orientação... então quando nós somos cobrados vai ter um desenvolvimento melhor (SR3).

(6) eu acho assim... nem tanto do professor dá o texto dizendo tudo sobre o assunto... mas dele orientar pra você ir atrás do que você quer escrever... por exemplo... eu tenho irmãs que estudam no ensino fundamental e médio e elas sempre recorrem a mim quando é pra pedir pra escrever redação... aí... essa semana minha irmã me procurou pra escrever um texto sobre as interfaces do Brasil... aí eu: "sim... você leu o que sobre o assunto?" "nada" "e como é que eu vou lhe ajudar se você não sabe do que você vai escrever?" "o tema é muito abrangente... você pode falar sobre muita coisa" (SR2).

Desse modo, os excertos revelam que, o plano de escrita, isto é, as orientações sistematizadas se refletem na mobilização efetiva da escrita pelos graduandos, como é sinalizado: "então quando nós somos cobrados, vai ter um desenvolvimento melhor" (RS3), mas também em uma maior segurança no que escreve e em confiança naquele que orienta. Além disso, é importante acrescentar que, diante desses excertos, o encaminhamento oferecido pelo professor formador não se caracteriza como uma relação de repetição ou falta de autonomia do aprendiz, em que os graduandos devem seguir à risca tudo o que é orientado; pelo contrário, trata-se de um norte, de um encaminhamento que permita ao que pratica eficaz engajamento com o tipo de escrita exigido no curso. Isso se confirma nos apontamentos de Assis (2016), a qual conclui que determinadas representações sociais favorecem determinados comportamentos, assim como determinados aspectos comportamentais favorecem determinadas representações.

Contudo, é interessante destacar que nem sempre o tratamento dado ao objeto de inserção recebe as devidas orientações, pois há situações em que os encaminhamentos são desconsiderados, gerando assim conflitos e dificuldades quanto à materialidade da escrita. Como uma espécie de denúncia, é possível identificar em alguns depoimentos a ausência de orientação ou a presença parcial que colabora para desajustes, como observamos a seguir: 
(7)é um orientado desorientado... porque "estuda autor tal... veja o que autor tal diz" mas o teu orientador... (va-mos colocar nesses modos...) ele não senta contigo para discutir pra ver profundamente o que o autor tal diz (SR2).

(8)então... nem sempre é orientada... então você tem que fazer... que é atividade pra nota... e aí? nem sempre é né? mas nem todos os casos não generalizando porque... tem professor que sempre conversa: "vá na minha sala" tem monitor "vá, tire dúvida!" mas nem sempre é (SR1).

(9)é tanto que quando a gente é solicitado a fazer algum tipo de gênero na academia... a gente quando não bem orientado... a gente sente dificuldade né? como eu vou fazer isso né? (SR3).

Com base nos excertos, parece-nos que, diante da necessidade de responder às atividades de produção típicas da esfera acadêmica, a escrita torna-se uma obrigação, que se apresenta a partir da falta de orientação. Desse modo, as exigências de elaboração textual são reclamadas pelos informantes, como podemos perceber nos excertos, o que lhes impõe buscar autonomia para a produção de textos. Neste sentido, a escrita é validada pelo produto, diante das exigências de produção, e desconsiderada pelo processo, dado o sucinto trabalho de orientação do professor, conforme se percebe nos depoimentos de denúncia. Essa visão de escrita orientada parece ser significativa nos depoimentos dos sujeitos da pesquisa, porque eles a consideram como um "orientando desorientado". Essa representação, vale lembrar, não é um saber difundido aceito por todo o grupo; no entanto, é possível que seja reconhecida como referência na comunidade (ou no grupo de participantes) em relação ao qual estes se situam (ASSIS, 2016).

Nesse sentido, os dados revelam informantes cuja expectativa seria a de que o professor é quem deveria fornecer oportunidades da vivência acadêmica para que, assim, o graduando, de fato, se inserisse na comunidade discursiva. Nesse sentido, a interação efetiva com o professor parece influenciar na construção de representações sobre a escrita nos cursos investigados, como mostra o excerto a seguir:

(10) essa ideia de orientar... porque:: tipo... associado aos professores... va-mos supor que: a gente tá pensando na escrita acadêmica... que a gente sempre tá em busca de melhoramento... aí: a gente vai para um determinado professor... ele diz: "olha, venha!" "chegue... é assim assim” aí ele explica toda a estrutura... 
essa prática faz com que a gente melhore (SR1).

Percebemos, nesse trecho, que o interesse para o melhoramento da escrita é traduzido pela necessidade de uma instrução fornecida, através dos comandos do professor, o que reforça a imagem de um ensino de escrita sistematizado, capaz de garantir aos graduandos, de acordo com os excertos, um efetivo desempenho.

\subsection{Escrita Acadêmica Normatizada}

Além desses conhecimentos evidenciados a partir de apontamentos dos informantes, outro mostrou-se com maior clareza, qual seja: escrita como um instrumento normatizado. Essa evidencia só foi possível, mediante a discussão gerada a respeito do entendimento dos informantes sobre a escrita recorrente nos cursos de Letras, pois, ao que foi revelado, quando o objeto investigado assume a função de inserir agentes nas práticas socializadas na formação inicial, é possível afirmar que este requer um estilo privilegiado pela comunidade na qual circula.

Assim, nos depoimentos, podemos identificar o que caracteriza a escrita como instrumento normatizado, conforme podemos comprovar a partir dos excertos de definição sobre norma:

(11) como eu posso dizer... monitorado... a gente analisar a escrita de ser normativo formal... é justamente essa questão de escrever de forma adequada... conforme a área... é: por se tratar de uma escrita acadêmica que requer isso... mais formal (SR1).

(12) então... a gente tem que tá aqui sempre pensando na norma... como aqui a gente é monitorado em relação às normas... também contam pra "equela questão do gênero... daquela forma também... de ter aquela forma de escrever uma resenha... tem que botar a referência primeiro... então: tudo isso tudo volta pra norma (SR3).

(13) UM PADRÃO... você não pode fugir desse padrão... a-go-ra... o que você escrever... se é longo... se é curto... vai depender do que você está sendo direcionado (SR2).

Como percebemos nos excertos, diante das exigências e particularidades típicas 
da dinâmica da academia, os informantes esclarecem que o lugar de formação oferece modos de escrituras os quais influenciam nas representações construídas. Os cursos focalizados, de acordo com esses colaboradores, impõem um padrão de escrita que monitora aqueles inseridos na comunidade científica, não podendo ser confundido com aqueles de bate-papo ou da escola, por exemplo. Diante do contato constante com as práticas típicas dessas comunidades, os agentes participantes, quando ativos e reflexivos, são influenciados a ponto de reproduzirem-no. Nesse sentido, o "indivíduo tanto é agente de mudança na sociedade como é um produto dessa sociedade" (FARR, 1994, p. 51).

Esse padrão interfere, inclusive, na forma como os principais gêneros utilizados na licenciatura em Letras apresentam-se, o que demanda significativo trabalho por parte dos graduandos. Entretanto, neste momento, cabe ressaltar que, mesmo com a norma, a escrita assume singularidades de área para área, bem como de gêneros textuais para gêneros textuais, pois, não há, neste caso, uma única forma de se socializar conhecimento, mesmo quando há uma norma de formatação que oriente a redação.

Não obstante, com base nos excertos, pudemos constatar que, uma vez preocupados em se inserirem nas práticas legitimadas pelos cursos em questão, os graduandos buscam adotar essa compreensão do objeto investigado, a fim de melhor gerar uma formação científica. Essa significação de escrita normatizada é construída a partir do momento em que os graduandos demonstram reconhecer que precisam se adaptar ao modo de escrita comum à formação que abarcam, baseados nos discursos, na forma, na estrutura, na linguagem e/ou nas técnicas com as quais projetam uma escrita com um viés mais normatizado.

Além do mais, essa especificidade de escrita é materializada em gêneros acadêmicos solicitados nos cursos, exemplificado com base na produção de uma resenha acadêmica, conforme é revelado no excerto 12: “em relação às normas também contam pra'aquela questão do gênero daquela forma também de ter aquela forma de escrever uma resenha" (RS3). Contudo, caso essa prática de escrita adotada pela academia não esteja em harmonia com as utilizadas pelos graduandos, dificilmente esses sujeitos terão êxito nesse contexto, cabendo a eles, assim, empenho e submissão às normas que vigoram nos cursos.

De acordo com esses excertos, percebemos a naturalização dessa convenção de escrita adotada nos cursos, pois, a fim de que seja assimilada pelos graduandos, é importante que tenha sido esclarecida e tratada com rigor. A percepção de escrita 
como instrumento normatizado, revelada nos dados, não parece estar relacionada apenas ao domínio do conteúdo condizente com o caráter científico do curso, pelo contrário, abarca tanto o aspecto formal - referente à estrutura da língua, à capacidade de expressão, como também ao enriquecimento do vocabulário quanto o aspecto científico - referente às exigências de adequação da escrita a eventos científicos -, como notamos a seguir:

(14) é voltando ao padrão... lá no ensino médio... não tem essa preocupação de/de... por exemplo... usar gírias... no ensino mé-dio... poderia fazer um texto usando gírias e aqui não... a não ser que seja exigido... esse tipo de ge/gênero... não é permitido se não for exigido... não é? complica você escrever com gírias... tem que ser uma forma culta... padrão... norma... técnico... produzir... na prova mesmo... você tem que se posi/posicionar corretamente... na produção de um artigo tem que ter um linguajar formal (SR3).

(15) $\operatorname{sim} . .$. porque nessa escrita acadêmica vai exigir uma norma... algumas estruturas pra escrever um texto... vamos dizer pra publi-car... você tem que seguir algumas normas... de letra... de tamanho... eu tô entendendo dessa forma (SR3).

Podemos depreender dos dados que esse instrumento normatizado assume uma forma praticada convencionada à comunicação com os pares, a qual é utilizada na academia. Essa percepção de escrita parece exigir atenção por parte de todos os atores envolvidos na comunidade científica, pois não se apresenta concluída, de modo que, quando direcionamos nossa atenção à linguagem, podemos considerar que essa rotulação se torna plural quando posta em discussão.

Normatizado, em suma, a partir do que já foi explanado, pode ser entendido de duas formas: como i) aspectos formais representados ou na configuração de gêneros circulantes na academia ou no estilo de escrita padrão; como ii) aspectos de formatação representado nas orientações técnicas de redação, como por exemplo a Associação Brasileira de Normas Técnicas (ABNT).

Ao analisarmos os depoimentos dos informantes, observamos que as evidências de compreensão sobre escrita desenvolvida nos cursos de Letras, tais como orientada e normatizada, correspondem às experiências do contato com esse objeto. Essas evidências acarretam estratégias de ação que são reveladas pelos graduandos como meio para se apropriar dos elementos particulares comuns ao 
estilo de escrita gerenciado na área profissional e que se torna singular mediante o nível de participação desses sujeitos. Por sua vez, esses conhecimentos formulados a partir de ideias e atitudes desempenhadas, quando a centralidade é a escrita, geram consequências no perfil desses agentes sociais, que permitem torná-los colaboradores dos conhecimentos socializados na prática do curso, ou seja, uma vez que a escrita seja entendida, a partir das representações discutidas nesta seção, possivelmente gera resultados que delineiam o perfil desses informantes, mas não somente isso, ressignifica também a relação existente entre o sujeito e o objeto representado.

\section{Conclusões}

Investigar acerca das representações sociais de graduandos a respeito da escrita em Letras permite-nos ouvir o que esses sujeitos têm a dizer sobre o artefato linguístico acadêmico que ora é didatizado, visto como objeto de ensino, ora é exigido, visto como objeto de inserção. Em vista disso, ao respondermos à questão de pesquisa Que representação social sobre a escrita em Letras é revelada por graduandos?, pudemos tornar mais inteligíveis questões a respeito das dificuldades com a escrita acadêmica, ainda pouco sistematizada na área de investigação científica. Desse modo, no tocante à questão, concluímos que os saberes evidenciam representações sociais de escrita que a caracterizam como objeto tanto de ensino, apresentado (e formalmente orientado) pelo professor, quanto de inserção, como meio para ressignificar práticas letradas naturalizadas na universidade.

Ao que foi possível perceber, essas evidências, quando refletidas no tratamento dado ao objeto de inserção na comunidade discursiva para graduandos, contribuem, de modo direto, tanto para a formação acadêmica quanto para a identidade profissional. Logo, para os sujeitos da pesquisa, a escrita é orientada quando há condições sociais de produção explícitas. Contudo, essas particularidades só podem ser executadas quando a escrita é normatizada, isto é, estruturada de acordo com as normas oficiais da área, o que resulta no reconhecimento e aceitação do dizer pelos membros da comunidade.

Além dessas evidências, os dados indiciam a utilização de estratégias de ação como maneira de tornar real o objeto representado. Assim, dentre as atitudes 
demonstradas pelos graduandos, reconhecemos a importância, por parte do professor formador, de condições sociossubjetivas de produção explícitas; e, por parte do aluno, o interesse em apoiar-se no currículo oficial de formação, como também na convenção de empregar da norma padrão. Isso posto, cabe dizer que é escrevendo que se aprende a escrever, pois, ao praticar a escrita acadêmica os sujeitos "aprendem" e "descobrem" a necessidade de orientação e normatização.

\title{
Social representations of writing in the undergraduate in letters course: object of teaching and insertion in the academic literacy practices
}

\begin{abstract}
This work is justified by the fact that it directs the attention to the learners who uses the writing to insert themselves in the diverse communicative practices common to the university. In these respects, motivated by the research problem that the social representation about writing in the Letters course is revealed by undergraduate students?, we have as objective to describe the representations of the academic writing in the Letters course in the light of the phenomenon of social representations developed by Moscovici (2013) and collaborators (JOVCHELOVITCH; GUARESCHI, 1994). The methodology is of qualitative basis, which follows the procedures of experimental (MICCOLI, 2004) and exploratory research (GIL, 1994). Concerning the data collection, 1 (one) questionnaire was conducted and 3 (three) reflective sessions were carried on with groups of undergraduate students enrolled in the course of Letters in 3 (three) institutions of higher education in the state of Paraíba, Brazil. The corpus is composed by a set of testimonials. The results show that the knowledge revealed by the undergraduate students works as a support for the elaboration of social representations of academic writing as a teaching object, proposed by the courses concerned; and the object of insertion in the literacy practices, requested in higher education.
\end{abstract}

Keywords: Academic writing. Social representations. Letters. Higher education courses. 
Referências

ADAM, Jean-Michel. Gêneros e sequências textuais. Paris: Nathan, 1992.

ARAÚJO, Denise Lino de; SILVA, Elizabeth Maria da. Redação de Vestibular em questão: práticas, conceitos, discursos e efeitos retroativos. Campina Grande: Bagagem, 2010.

ASSIS, Juliana Alves. Representações sociais e letramento. In: KLEIMAN, Angela B.; ASSIS, Juliana Alves (Org.). Significados e ressignificações do letramento: desdobramentos de uma perspective sociocultural sobre a escrita. Campinas, SP: Mercado de Letras, 2016. p. 63-88.

BAZERMAN, Charles. Retórica da ação letrada. São Paulo: Parábola, 2015. BAZERMAN, Charles. Teoria da ação letrada. São Paulo: Parábola, 2015. BORTONI-RICARDO, Stella Maris. O professor pesquisador: introdução à pesquisa quantitativa. São Paulo: Parábola. 2008.

BRONCKART, Jean-Paul. Introdução. In: BRONCKART, Jean-Paul. Atividade de linguagem, discurso e desenvolvimento humano. Campinas, SP: Mercado de Letras, 2006. p. 10-23.

BRONCKART, Jean-Paul. O agir nos discursos: das concepções teóricas às concepções dos trabalhadores. Campinas, SP: Mercado de Letras, 2008.

BRONCKART, Jean-Paulo. Quadro e questionamento epistemológicos. In: BRONCKART, Jean-Paul. Atividade de linguagem, textos e discursos: por um interacionismo sociodiscursivo. 2. ed. São Paulo: EDUC, 2012. p. 21-67. Original publicado em 1999.

FARR, Robert M. Representações sociais: a teoria e sua história. In: GUARESCHI, Pedrinho A.; JOVCHELOVITCH, Sandra (Org.). Textos em representações sociais. Petrópolis, RJ: Vozes, 1994. p. 31-59.

GIL, Antonio Carlos. Métodos e técnicas de pesquisa social. São Paulo: Atlas, 1994.

HEMAIS, Barbara; BIASI-RODRIGUES, Bernadete. A proposta sociorretórica de John M. Swales para o estudo de gêneros textuais. In: MEURER, José Luiz; BONINI, Adair; MOTTA-ROTH, Désirée (Org.). Gêneros: teorias, métodos, debates. São Paulo: Parábola, 2005. 
HOFFNAGEL, Judith Chambliss. Temas em antropologia e linguística. Recife: Bagaço, 2010.

LIBERALI, Fernanda Coelho; MAGALHÃES, Maria Cecília Camargo; ROMERO, Tânia Regina de Souza. Autobiografia, diário e sessão reflexiva: atividades na formação crítico-reflexiva de professores. In: BARBARA, Leila; RAMOS, Rosinda de Castro Guerra (Org.). Reflexão e ações no ensino-aprendizagem de línguas. Campinas, SP: Mercado de letras, 2003. p. 103-129.

MARCUSCHI, Luiz Antonio. Gêneros textuais: definição e funcionalidade. In: DIONISIO, Angela Paiva; MACHADO, Anna Rachel; BEZERRA, Maria Auxiliadora. Gêneros textuais e ensino. São Paulo: Parábola, 2010. p. 19-38.

MARCUSCHI, Luiz Antonio. Gêneros textuais: definição e funcionalidade. In: DIONISIO, Angela Paiva; MACHADO, Anna Rachel; BEZERRA, Maria Auxiliadora. Gêneros textuais e ensino. São Paulo: Parábola, 2010. p. 19-38.

MARCUSCHI, Luiz Antonio. Produção textual, análise de gêneros e compreensão. São Paulo: Parábola, 2008.

MARCUSCHI, Luiz Antonio. Análise da conversação. 5. ed. São Paulo: Ática, 2001.

MENEGASSI, Renilson José. Professor e escrita: a construção de comandos de produção de textos. Trabalhos em Linguística Aplicada, Campinas, n. 42, jul./ dez. 2003.

MENEGASSI, Renilson José; OHUSCHI, Márcia Cristina Greco. O aprender a ensinar a escrita no curso de letras. Atos de pesquisa em educação, PPGE/ME, FURB, v. 2, n. 2, maio/ago. 2007.

MICCOLI, Laura A. Pesquisa experiencial em contextos de aprendizagem: uma abordagem em evolução. São Paulo: Pontes, 2014.

MOSCOVICI, Serge. Representações Sociais: investigações em psicologia social. 10. ed. Petrópolis; Rio de Janeiro: Vozes, 2013. p. 29-109. Original publicado em 1961.

MOTTA-ROTH, Desirée; HENDGES, Graciela Rabuske. Produção textual na universidade. São Paulo: Parábola Editorial, 2010.

PY, Bernard. Introduction. In: CAVALLI, Marisa; COLETTA, D.; GAJO, Laurent; MATTHEY, M; SERRA, C. (Org.). Langues, bilinguisme et representations socials au Val d'Aoste. Aoste: Istituto Regionale di Ricerca Educativa, Documents, 2003. p. 15-33. 
ROTTAVA, Lúcia. Concepções de leitura e de escrita: um contraponto entre professores em formação de português, inglês e espanhol. In: ROTTAVA, Lúcia; LIMA, Marília dos Santos. Linguística aplicada: relacionando teoria e prática no ensino de línguas, Ijuí, Unijuí, p. 111-137, 2004.

SÁ, Celso Pereira de. Representações Sociais: o conceito e o estado atual da teoria. In: SPINK, Mary Jane (Org.). O conhecimento no cotidiano: as representações na perspectiva da psicologia social. São Paulo: Brasiliense, 1995. p. 19-45.

SILVA, Marcelo Clemente. Gêneros da Escrita Acadêmica: questões sobre ensino e aprendizagem. In: REINALDO, Maria Augusta; MARCUSCHI, Beth; DIONISIO, Angela. Gêneros textuais: práticas de pesquisa e práticas de ensino. Recife: Ed. Universitária da UFPE, 2012. p. 97-115.

TRAVAGLIA, Luiz Carlos. Tipelementos e a construção de uma teoria tipológica geral de textos. In: FÁVERO, Leonor Lopes; BASTOS, Neusa M. de O. Barbosa; MARQUESI, Sueli Cristina (Org.). Língua Portuguesa pesquisa e ensino. São Paulo: EDUC/FAPESP, 2002. v. 2, p. 97- 117.

TRINDADE, Zeidi Araujo; SANT 